\title{
Respiratory parameters predict poor outcome in COPD patients, category GOLD 2017 B
}

This article was published in the following Dove Press journal: International Journal of COPD

\author{
Kristian Brat ${ }^{\prime}$ \\ Marek Plutinsky' \\ Karel Hejduk ${ }^{2}$ \\ Michal Svoboda ${ }^{2}$ \\ Patrice Popelkova ${ }^{3}$ \\ Jaromir Zatloukal ${ }^{4}$ \\ Eva Volakova ${ }^{4}$ \\ Miroslava Fecaninova ${ }^{5}$ \\ Lucie Heribanova ${ }^{6}$ \\ Vladimir Koblizek ${ }^{7}$ \\ 'Department of Respiratory \\ Diseases, Faculty of Medicine, \\ University Hospital Brno, Masaryk \\ University, Brno, Czech Republic; \\ ${ }^{2}$ Faculty of Medicine, Institute of \\ Biostatistics and Analyses, Masaryk \\ University, Brno, Czech Republic; \\ ${ }^{3}$ Pulmonary Department, University \\ Hospital, Ostrava, Czech Republic; \\ ${ }^{4}$ Pulmonary Department, University \\ Hospital, Olomouc, Czech Republic; \\ ${ }^{5}$ Department of Pneumology, Bulovka \\ Hospital, Prague, Czech Republic; \\ ${ }^{6}$ Department of Respiratory Medicine, \\ Thomayer Hospital, Prague, Czech \\ Republic; ${ }^{7}$ Pulmonary Department, \\ Faculty of Medicine in Hradec \\ Kralove, University Hospital \\ Hradec Kralove, Charles University, \\ Hradec Kralove, Czech Republic
}

\begin{abstract}
Background: Respiratory parameters are important predictors of prognosis in the COPD population. Global Initiative for Obstructive Lung Disease (GOLD) 2017 Update resulted in a vertical shift of patients across COPD categories, with category B being the most populous and clinically heterogeneous. The aim of our study was to investigate whether respiratory parameters might be associated with increased all-cause mortality within GOLD category B patients.
\end{abstract}

Methods: The data were extracted from the Czech Multicentre Research Database, a prospective, noninterventional multicenter study of COPD patients. Kaplan-Meier survival analyses were performed at different levels of respiratory parameters (partial pressure of oxygen in arterial blood $\left[\mathrm{PaO}_{2}\right]$, partial pressure of arterial carbon dioxide $\left[\mathrm{PaCO}_{2}\right]$ and greatest decrease of basal peripheral capillary oxygen saturation during 6-minute walking test [6-MWT]) Univariate analyses using the Cox proportional hazard model and multivariate analyses were used to identify risk factors for mortality in hypoxemic and hypercapnic individuals with COPD.

Results: All-cause mortality in the cohort at 3 years of prospective follow-up reached $18.4 \%$. Chronic hypoxemia $\left(\mathrm{PaO}_{2}<7.3 \mathrm{kPa}\right)$, hypercapnia $\left(\mathrm{PaCO}_{2}>7.0 \mathrm{kPa}\right)$ and oxygen desaturation during the 6-MWT were predictors of long-term mortality in COPD patients with forced expiratory volume in 1 second $\leq 60 \%$ for the overall cohort and for GOLD B category patients. Univariate analyses confirmed the association among decreased oxemia $(<7.3 \mathrm{kPa})$, increased capnemia ( $>7.0 \mathrm{kPa}$ ), oxygen desaturation during 6-MWT and mortality in the studied groups of COPD subjects. Multivariate analysis identified $\mathrm{PaO}_{2}<7.3 \mathrm{kPa}$ as a strong independent risk factor for mortality.

Conclusion: Survival analyses showed significantly increased all-cause mortality in hypoxemic and hypercapnic GOLD B subjects. More important, $\mathrm{PaO}_{2}<7.3 \mathrm{kPa}$ was the strongest risk factor, especially in category B patients. In contrast, the majority of the tested respiratory parameters did not show a difference in mortality in the GOLD category D cohort.

Keywords: mortality, hypoxemia, hypercapnia, COPD, GOLD 2017 update

\section{Introduction}

COPD is a major health problem affecting $11.7 \%$ of the global population and causing the death of about 3 million persons annually. ${ }^{1}$ Currently, the Global Initiative for Obstructive Lung Disease (GOLD) introduced a new approach in COPD classification by using separate evaluations of spirometric values (stages 1-4) and the presence of symptoms and exacerbations (categories A-D). ${ }^{1}$ Application of the new GOLD 2017 recommendations profoundly affected the distribution of patients in the A-D groups. An obvious consequence of the new classification is a vertical shift of a large portion of COPD patients from the $\mathrm{C}$ to the $\mathrm{A}$ group and from the $\mathrm{D}$ to the 
B group. Thus, more than half of the real-life COPD population represents substantially heterogeneous B category. ${ }^{2}$

Several risk factors predictive of poor outcome have been identified for stratification of stable COPD patients. Lung function, represented by forced expiratory volume in 1 second $\left(\mathrm{FEV}_{1}\right)$, has been the most widely used prognostic factor and still has an important role in the assessment of COPD patients. ${ }^{1,3-6}$ Other prognostic factors associated with an increased risk of death include low exercise tolerance, a high degree of functional breathlessness and a low body mass index (BMI). ${ }^{5}$ In 2004, Celli et al published an integrative, multidimensional prognostic model for COPD patients named the BODE index (BMI, Obstruction, Dyspnea and Exercise). ${ }^{5}$ Subsequently, the COTE (COPD-specific comorbidity test) index, involving the BODE index and comorbidities assessment, has been introduced. ${ }^{4}$ Other scoring instruments may also be predictive of poor outcomes. In a Swedish multicenter study, a Clinical COPD Questionnaire score higher than 2 was associated with a prognosis of higher mortality. ${ }^{7}$ Since 2011, GOLD recommends stratification of COPD patients into A-D categories; ${ }^{8}$ however, prognostic values of BODE and COTE indices have been found superior to GOLD 2011 A-D categories. ${ }^{4}$ Two important studies revealed the shortcomings of GOLD 2011 classification. In the Evaluation of COPD Longitudinally to Identify Predictive Surrogate Endpoints (ECLIPSE) study as well as in the Copenhagen City Heart Study, no advantages over GOLD 1-4 classification were demonstrated with the introduction of GOLD A-D categories in better predicting long-term mortality. ${ }^{9,10}$

The latest GOLD 2017 Update does not recommend the use of elementary respiratory parameters for disease classification or for mortality risk assessment or treatment strategy improvement. ${ }^{1}$ However, chronic respiratory failure is a frequent feature (or rather consequence) of the disease, and the presence of chronic hypoxemia and/or hypercapnia is associated with remarkably higher mortality and morbidity. ${ }^{3}$ Hypoxemia is a state in which partial pressure of oxygen in arterial blood $\left(\mathrm{PaO}_{2}\right)$ is decreased below the reference values adjusted for age. Limits between normal and abnormal $\mathrm{PaO}_{2}$ decrease with age. Hypercapnia is defined by partial pressure of arterial carbon dioxide $\left(\mathrm{PaCO}_{2}\right)>6 \mathrm{kPa} .{ }^{11,12}$

Various respiratory parameters have been assessed as potential risk factors for mortality by a large number of studies. However, there is limited evidence of how respiratory parameters affect outcome in specific subgroups of COPD subjects. The general purpose of the Czech Multicentre Research Database (CMRD) of the COPD project was to analyze the association among respiratory parameters, clinical phenotypes, GOLD categories and all-cause mortality in COPD individuals. The primary aim of the presented study was to assess selected respiratory parameters as potential predictors of death in COPD patients, classified according to the new GOLD 2017 strategy with emphasis on the largest population of COPD individuals: GOLD 2017 category B patients.

\section{Methods}

\section{Study design}

All patients for the study were recruited from the CMRD of COPD. This project (registered by the State Institute for Drug Control under the identifier 1301100001 and at ClinicalTrials.gov as NCT01923051) was initiated in August 2013. ${ }^{13}$ The prospective CMRD study is being conducted in full accordance with Czech and European Union laws. The CMRD study and its protocol were approved by The Multicentre Ethical Committee of Masaryk University, Brno, Czech Republic (approval date: JAN-16-2013, protocol code: CHOPN) as well as ethics and regional review boards of all individual participating centers. ${ }^{13}$ All COPD participants signed a written consent form before study enrolment.

Basic criteria for patient enrolment were respiratory physician's diagnosis of COPD at least 12 months before enrolment, post-bronchodilator $\mathrm{FEV}_{1} \leq 60 \%$, exacerbationfree period for at least 8 weeks and patient's written consent. We used the GOLD definition of COPD case, that is, a patient with confirmed post-bronchodilator airflow limitation $\left(\mathrm{FEV}_{1} /\right.$ forced vital capacity $<0.70$ ). Patient recruitment finished in December 2016. Longitudinal and prospective follow-up (in regular 6-month periods) of patients is planned for 5 consecutive years and will be finished in $2021 .{ }^{13}$ At each control, the patients completed pulmonary function tests, an elementary physical examination, measurement of respiratory and nonrespiratory symptoms and systematic assessment of the patient's history. Completing a 6-minute walking test (6-MWT) and/or an arterial blood gas (ABG) analysis was optional (not mandatory). ${ }^{13}$ If done, ABG analysis and/or a 6-MWT were performed without oxygen supplementation in all cases. Any changes in medication, onset of new comorbidities or number of exacerbations were recorded. The prospective nature of the project enabled assessment of various outcomes, including long-term mortality and exacerbation rates, to follow the development of multiple comorbidities as well as to understand the natural evolution of the disease and its manifestations (represented by various clinical phenotypes and GOLD categories). ${ }^{13}$ 
In this particular study, the following respiratory parameters were selected for mortality analyses: $\mathrm{PaO}_{2}$, $\mathrm{PaCO}_{2}$, arterial potential of hydrogen $(\mathrm{pH})$, basal peripheral capillary oxygen saturation $\left(\mathrm{SpO}_{2}\right)$, minimal $\mathrm{SpO}_{2}$ during a 6-MWT, greatest decrease in $\mathrm{SpO}_{2}$ during a 6-MWT and the presence of desaturation (ie, at least $4 \%$ drop and/or decrease of $\mathrm{SpO}_{2}<90 \%$ during 6-MWT).

\section{Study population}

Inclusion criteria for our analyses were regular follow-up in the CMRD. Exclusion criteria were the presence of sleep apnea syndrome or systolic pulmonary arterial hypertension $(\mathrm{PAH})>60 \mathrm{mmHg}$ (in patient history and/or echocardiographic finding of $\mathrm{PAH}>60 \mathrm{mmHg}$ during the study enrolment).

\section{Statistical analyses}

For a basic description of the study population, categorical parameters are presented as absolute (relative) frequencies. Relative frequencies are calculated from valid $N$. Continuous variables are described by valid $N$, using mean with SD and median supplemented by 5 th and 95 th percentiles.

Kaplan-Meier curves illustrating 3-year survival were calculated for survival analysis of patients in the complete cohort along with groups A-D according to the GOLD 2016 and GOLD 2017 guidelines for these parameters: $\mathrm{PaO}_{2}$ (oxemia), $\mathrm{PaCO}_{2}$ (capnemia), arterial $\mathrm{pH}$, basal $\mathrm{SpO}_{2}$, minimal $\mathrm{SpO}_{2}$ during (after) 6-MWT, greatest decrease of $\mathrm{SpO}_{2}$ during 6-MWT and the presence of desaturation during 6-MWT. The figures are supplemented by numerical data showing proportion of survival at 6, 12, 24 and 36 months of follow-up. Differences in survival between groups were tested by log-rank test.

Correlations of blood gases $\left(\mathrm{PaO}_{2}, \mathrm{PaCO}_{2}\right.$, basal $\mathrm{SpO}_{2}$, minimal $\mathrm{SpO}_{2}$ during (after) 6-MWT and greatest decrease of $\mathrm{SpO}_{2}$ during 6-MWT) were analyzed by Spearman's coefficient of correlation. In addition, the best calculated cutoff values of oxemia, capnemia, blood $\mathrm{pH}$, basal $\mathrm{SpO}_{2}$, minimal $\mathrm{SpO}_{2}$ during (after) 6-MWT and greatest decrease of $\mathrm{SpO}_{2}$ during 6-MWT were calculated for prediction for mortality.

A Cox proportional hazard model was used to assess risk factors for mortality. Multivariate models analyzed other potential predictors of all-cause mortality for patient groups with hypoxemia, three levels of capnemia and desaturation during a 6-MWT.

Analyses were performed using SPSS Statistics 24.0 software with the level of significance at $\alpha=0.05$.

\section{Results}

Of the 784 patients included in the CMRD (by December 2016), 53 patients were excluded because of the presence of sleep apnea syndrome and six patients because of severe PAH (Figure 1). Of the remaining 725 patients, the inclusion criteria for the proposed analyses of ABGs were met in 391 patients and for $\mathrm{SpO}_{2}$ in 552 patients.

\section{Patients' characteristics}

Basic demographic characteristics included sex, age at inclusion, age at COPD diagnosis, BMI and smoking status (Table 1). Seventy-two percent of the study population were men, $89 \%$ were past or current smokers, median age was 67.1 years and median BMI was 26.5. The most frequently reported symptoms were cough (72\%), expectoration (58\%) and fatigue (47\%). Mean exacerbation rate was 1.2 events per year, one-third ( 0.4 event per year) of these requiring hospitalization. Lung function tests showed that the median $\mathrm{FEV}_{1}$ was $46 \%$ of predicted value (pred), and median transfer factor for carbon monoxide was $51 \%$ pred, whereas median distance covered during a 6-MWT was $359.5 \mathrm{~m}$ (Table 1).

\section{Respiratory parameters}

Table 2 summarizes the results of ABG analyses and the results of pulse oximetry performed at rest and during a 6-MWT. Correlation analyses of respiratory parameters showed significant and strong correlation between $\mathrm{PaO}_{2}$ and basal and minimal $\mathrm{SpO}_{2}$ and a significant negative correlation between $\mathrm{PaO}_{2}$ and $\mathrm{PaCO}_{2}$ for the complete study cohort and for GOLD 2017 group B (Table 3).

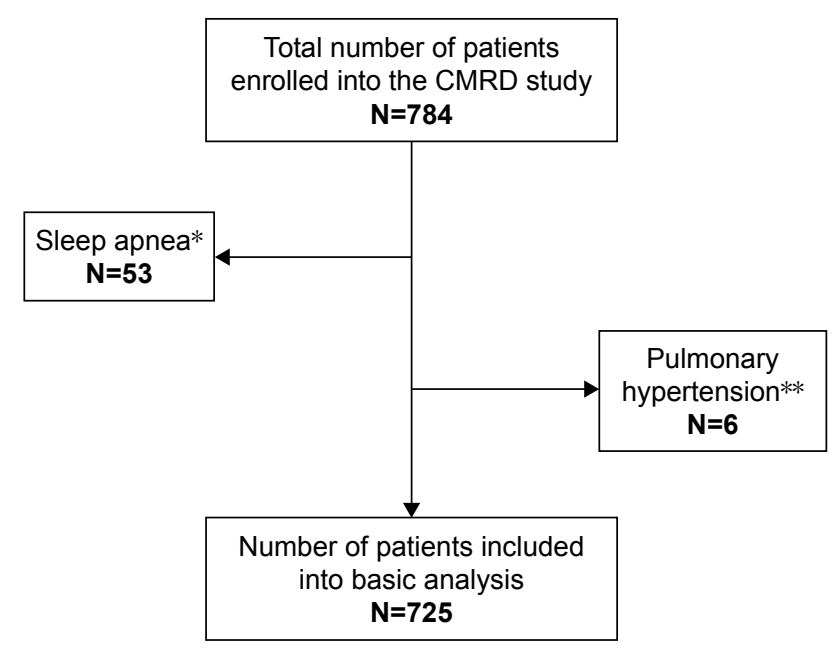

Figure I Flow chart of patients

Notes: *Self-reported history of sleep apnea. **Self-reported history of pulmonary hypertension.

Abbreviation: CMRD, Czech Multicentre Research Database. 
Table I Basic characteristics of the study cohort - COPD patients $(n=725)$

\begin{tabular}{|c|c|}
\hline \multicolumn{2}{|l|}{ Demography } \\
\hline Sex - men & $520(71.7 \%)$ \\
\hline Age at inclusion & $\mathrm{n}=725 ; 66.7(9.4)$ \\
\hline BMI & $\mathrm{n}=725 ; 26.9(5.8)$ \\
\hline \multicolumn{2}{|l|}{ Smoking status } \\
\hline Ex-smoker & 491 (67.7\%) \\
\hline Nonsmoker & $79(10.9 \%)$ \\
\hline Current smoker & $155(2 \mid .4 \%)$ \\
\hline \multicolumn{2}{|l|}{ Symptoms } \\
\hline \multicolumn{2}{|l|}{ Dyspnea - mMRC } \\
\hline 0 & $36(5.0 \%)$ \\
\hline 1 & $14 \mid(19.4 \%)$ \\
\hline 2 & $289(39.9 \%)$ \\
\hline 3 & $150(20.7 \%)$ \\
\hline 4 & $109(15.0 \%)$ \\
\hline CAT & $\mathrm{n}=7 \mid 5 ; 16.0(7.8)$ \\
\hline Fatigue & $331(46.8 \%)$ \\
\hline Cough & $521(71.9 \%)$ \\
\hline Expectoration & $423(58.3 \%)$ \\
\hline Atopy & $86(11.9 \%)$ \\
\hline Asthma & $75(10.3 \%)$ \\
\hline \multicolumn{2}{|c|}{ Exacerbations in the last 12 months } \\
\hline Treated at home & $\mathrm{n}=725 ; 0.8(1.3)$ \\
\hline Requiring hospitalization & $\mathrm{n}=725 ; 0.4(0.8)$ \\
\hline Total & $\mathrm{n}=725 ; 1.2(1.6)$ \\
\hline \multicolumn{2}{|l|}{ Lung functions } \\
\hline $\mathrm{FEV}_{1}(\%$ pred $)$ & $\mathrm{n}=725 ; 44.9(\mathrm{I} I .6)$ \\
\hline FVC (\% pred) & $\mathrm{n}=725 ; 69.2(17.7)$ \\
\hline $\mathrm{FEV}_{1} / \mathrm{FVC}(\%)$ & $\mathrm{n}=725 ; 0.5(0.1)$ \\
\hline RV (\% pred) & $\mathrm{n}=587 ; 189.0(58.7)$ \\
\hline TLC (\% pred) & $\mathrm{n}=583 ; \mathrm{I} \mid 2.1(25.8)$ \\
\hline IC/TLC (\%) & $\mathrm{n}=422 ; 42.1$ (24.6) \\
\hline $\mathrm{TL}_{\mathrm{co}}(\%$ pred $)$ & $\mathrm{n}=473 ; 52.5(22.1)$ \\
\hline $\mathrm{FeNO}(\mathrm{ppb})$ & $\mathrm{n}=267 ; 18.6(19.4)$ \\
\hline 6-MWD (m) & $\mathrm{n}=552 ; 334.9(131.7)$ \\
\hline
\end{tabular}

\section{Phenotypes}

Czech approach (one COPD subject $=$ one or more "phenotypical labels - treatable traits")

$\begin{array}{ll}\text { Bronchitic } & 423(58.3 \%) \\ \text { Emphysematous } & 263(78.0 \%) \\ \text { BCOS } & 105(31.9 \%) \\ \text { ACOS* } & 23(4.1 \%) \\ \text { Frequent exacerbators } & 225(31.0 \%) \\ \text { Cachexia } & 111(15.3 \%)\end{array}$

Spanish approach (one COPD subject = one "clinical phenotype") $\mathrm{ACOS}^{* *}$

Non-AE

$A E C B$

$\mathrm{AE}$ non- $\mathrm{CB}$

GOLD

GOLD 2016 (A-D)

$\begin{array}{ll}\text { A } & 34(4.9 \%) \\ B & 140(20.2 \%) \\ \text { C } & 37(5.3 \%) \\ \text { D } & 483(69.6 \%)\end{array}$

Table I (Continued)

\begin{tabular}{cl}
\hline GOLD 2017 (A-D) & \\
A & $60(8.3 \%)$ \\
B & $383(53.0 \%)$ \\
C & $14(1.9 \%)$ \\
D & $265(36.7 \%)$
\end{tabular}

Notes: Categorical parameters are described by absolute (relative) frequencies. Relative frequencies are calculated from valid data. Continuous parameters are described by valid $\mathrm{N}$, mean (SD). ${ }^{*}$ Czech approach has used more restrictive criteria $^{13}$ than simplified. **Spanish approach. ${ }^{15}$

Abbreviations: 6-MWD, 6 minute walking distance; ACOS (ACO), asthma COPD overlap syndrome; $A E C B$, frequent exacerbators with chronic bronchitis; $A E$ non- $C B$, frequent exacerbators without chronic bronchitis; $B C O S$, bronchiectases COPD overlap syndrome; BMI, body mass index; CAT, COPD Assessment Test; FeNO, fractional exhaled nitric oxide; FEV , forced expiratory volume in I second; FVC, forced vital capacity; GOLD, Global Initiative for Obstructive Lung Disease; IC/TLC, inspiratory capacity to total lung capacity ratio; mMRC, modified Medical Research Council dyspnea scale; ppb, part per billion; pred, predicted value; RV, residual volume; $\mathrm{TLC}$, total lung capacity; $\mathrm{TL}_{\mathrm{co}}$, transfer factor for carbon monoxide.

\section{Survival analyses}

Of the tested respiratory parameters, minimal $\mathrm{SpO}_{2}$ during the 6-MWT yielded the highest ability to predict mortality (area under curve $0.631 ; p<0.001$; Table 4). Survival analyses showed significant differences in long-term all-cause mortality in relation to the selected respiratory parameters $\left(\mathrm{PaO}_{2}, \mathrm{PaCO}_{2}\right.$ and desaturation during a 6-MWT; Figures $2 \mathrm{~A}-\mathrm{C}, 3 \mathrm{~A}-\mathrm{C}$ and $4 \mathrm{~A}-\mathrm{C})$.

\section{$\mathrm{PaO}_{2}$}

Significant association has been found between severe hypoxemia $\left(\mathrm{PaO}_{2}<7.3 \mathrm{kPa}\right)$ and all-cause mortality in the complete COPD cohort ( $p<0.001$; Figure $2 \mathrm{~A})$ as well as in the GOLD 2017 B category ( $p=0.001$; Figure $2 \mathrm{~B}$ ). In contrast, severe hypoxemia $\left(\mathrm{PaO}_{2}<7.3 \mathrm{kPa}\right)$ did not result in a significant difference in all-cause mortality in the COPD 2017 D category ( $p=0.061$; Figure 2C).

\section{$\mathrm{PaCO}_{2}$}

In GOLD 2017 category B patients, the highest survival rate was observed if the level of $\mathrm{PaCO}_{2}$ was 5-7 $\mathrm{kPa}$.

Table 2 Respiratory parameters $(n=725)$

\begin{tabular}{ll}
\hline Respiratory parameters & \\
$\mathrm{PaO}_{2}(\mathrm{kPa})$ & $\mathrm{n}=391 ; 8.8(\mathrm{I} .6)$ \\
$\mathrm{PaCO}_{2}(\mathrm{kPa})$ & $\mathrm{n}=391 ; 5.2(0.9)$ \\
$\mathrm{pH}$ & $\mathrm{n}=391 ; 7.42(0.43)$ \\
$\mathrm{Basal} \mathrm{SpO}_{2}(\%)$ & $\mathrm{n}=552 ; 94.5(3.6)$ \\
Minimal $\mathrm{SpO}_{2}$ during (after) 6-MWT (\%) & $\mathrm{n}=552 ; 89.6(7.0)$ \\
Greatest decrease of $\mathrm{SpO}_{2}$ during 6-MWT (\%) & $\mathrm{n}=552 ; 4.8(4.7)$ \\
\hline
\end{tabular}

Note: Continuous parameters are described by valid $N$, mean (SD).

Abbreviations: 6-MWT, 6-minute walking test; $\mathrm{PaCO}_{2}$, partial pressure of arterial carbon dioxide; $\mathrm{PaO}_{2}$, partial pressure of arterial oxygen; $\mathrm{pH}$, arterial potential of hydrogen; $\mathrm{SpO}_{2}$, peripheral capillary oxygen saturation. 
Table 3 Correlation of respiratory parameters (all patients and GOLD 2017 B patients)

\begin{tabular}{|c|c|c|c|c|c|}
\hline All patients & $\mathrm{PaO}_{2}(\mathrm{kPa})$ & $\mathrm{PaCO}_{2}(\mathrm{kPa})$ & Basal SpO $(\%)$ & Minimal $\mathrm{SpO}_{2}(\%)$ & Greatest decrease of $\mathrm{SpO}_{2}(\%)$ \\
\hline \multirow[t]{2}{*}{$\mathrm{PaO}_{2}(\mathrm{kPa})$} & - & $n=391$ & $n=351$ & $n=351$ & $n=35 I$ \\
\hline & & $-0.306(<\mathbf{0 . 0 0 1})$ & $0.552(<0.001)$ & $0.535(<0.001)$ & $-0.367(<\mathbf{0 . 0 0 1})$ \\
\hline \multirow[t]{2}{*}{$\mathrm{PaCO}_{2}(\mathrm{kPa})$} & $n=391$ & - & $n=351$ & $n=351$ & $n=351$ \\
\hline & $-0.306(<\mathbf{0 . 0 0 I})$ & & $-0.274(<0.001)$ & $-0.298(<0.001)$ & $0.219(<0.001)$ \\
\hline \multirow[t]{2}{*}{ Basal $\mathrm{SpO}_{2}(\%)$} & $n=351$ & $n=351$ & - & $\mathrm{n}=552$ & $n=552$ \\
\hline & $0.552(<\mathbf{0 . 0 0 I})$ & $-0.274(<\mathbf{0 . 0 0 1})$ & & $0.742(<0.001)$ & $-0.350(<\mathbf{0 . 0 0 1})$ \\
\hline \multirow[t]{2}{*}{ Minimal $\mathrm{SpO}_{2}(\%)$} & $\mathrm{n}=35 \mathrm{I}$ & $n=351$ & $n=552$ & - & $n=552$ \\
\hline & $0.535(<0.00 \mathrm{I})$ & $-0.298(<0.001)$ & $0.742(<0.00 \mathrm{I})$ & & $-0.860(<0.001)$ \\
\hline \multirow[t]{2}{*}{ Greatest decrease of $\mathrm{SpO}_{2}(\%)$} & $n=351$ & $n=351$ & $n=552$ & $\mathrm{n}=552$ & - \\
\hline & $-0.367(<\mathbf{0 . 0 0 I})$ & $0.219(<0.001)$ & $-0.350(<\mathbf{0 . 0 0 1})$ & $-0.860(<0.001)$ & \\
\hline \multicolumn{6}{|l|}{ GOLD 2017 B patients } \\
\hline \multirow[t]{2}{*}{$\mathrm{PaO}_{2}(\mathrm{kPa})$} & - & $n=181$ & $\mathrm{n}=168$ & $n=168$ & $n=168$ \\
\hline & & $-0.345(<\mathbf{0 . 0 0 1})$ & $0.462(<0.001)$ & $0.477(<0.00 \mathrm{I})$ & $-0.338(<\mathbf{0 . 0 0 1})$ \\
\hline \multirow[t]{2}{*}{$\mathrm{PaCO}_{2}(\mathrm{kPa})$} & $n=|8|$ & - & $n=168$ & $n=168$ & $n=168$ \\
\hline & $-0.345(<\mathbf{0 . 0 0 I})$ & & $-0.303(<\mathbf{0 . 0 0 1})$ & $-0.279(<\mathbf{0 . 0 0 1})$ & $0.167(0.030)$ \\
\hline \multirow[t]{2}{*}{ Basal $\mathrm{SpO}_{2}(\%)$} & $n=168$ & $n=168$ & - & $\mathrm{n}=287$ & $\mathrm{n}=287$ \\
\hline & $0.462(<0.001)$ & $-0.303(<\mathbf{0 . 0 0 1})$ & & $0.738(<0.00 \mathrm{I})$ & $-0.35 \mathrm{I}(<\mathbf{0 . 0 0} \mathrm{I})$ \\
\hline \multirow[t]{2}{*}{ Minimal $\mathrm{SpO}_{2}(\%)$} & $n=168$ & $n=168$ & $\mathrm{n}=287$ & - & $\mathrm{n}=287$ \\
\hline & $0.477(<0.00 \mathrm{I})$ & $-0.279(<\mathbf{0 . 0 0 1})$ & $0.738(<0.001)$ & & $-0.853(<\mathbf{0 . 0 0 1})$ \\
\hline \multirow[t]{2}{*}{ Greatest decrease of $\mathrm{SpO}_{2}(\%)$} & $n=168$ & $n=168$ & $\mathrm{n}=287$ & $\mathrm{n}=287$ & - \\
\hline & $-0.338(<\mathbf{0 . 0 0 I})$ & $0.167(0.030)$ & $-0.35 \mathrm{I}(<\mathbf{0 . 0 0} \mathrm{I})$ & $-0.853(<0.001)$ & \\
\hline
\end{tabular}

Notes: Spearman's coefficient of correlation. Significant differences are indicated in bold.

Abbreviations: $\mathrm{PaCO}_{2}$, partial pressure of arterial carbon dioxide; $\mathrm{PaO}_{2}$, partial pressure of arterial oxygen; SpO , peripheral capillary oxygen saturation.

The presence of hypercapnia $\left(\mathrm{PaCO}_{2}>7 \mathrm{kPa}\right)$ significantly increased $(p<0.001)$ the mortality rate in this group. Interestingly, there was no effect of capnemia on all-cause mortality in the complete cohort $(p=0.290)$ or in the GOLD 2017 category D group $(p=0.409)$ (Figure $3 \mathrm{~A}-\mathrm{C})$.

\section{$\mathrm{pH}$}

$\mathrm{pH}$ was not found to be associated with increased risk for mortality in any of the tested patient groups.

\section{Desaturation during 6-MWT}

Desaturation was present in $46.4 \%$ of the study cohort (Table S1). The presence of desaturation was associated

Table 4 Prediction of all-cause mortality by respiratory parameters

\begin{tabular}{|c|c|c|}
\hline Respiratory parameters & AUC (95\% Cl) & p-value \\
\hline $\mathrm{PaO}_{2}(\mathrm{kPa})$ & $0.590(0.507 ; 0.673)$ & 0.020 \\
\hline $\mathrm{PaCO}_{2}(\mathrm{kPa})$ & $0.600(0.521 ; 0.679)$ & 0.010 \\
\hline Basal $\mathrm{SpO}_{2}(\%)$ & $0.607(0.537 ; 0.676)$ & 0.002 \\
\hline Minimal $\mathrm{SpO}_{2}$ during 6-MWT (\%) & $0.631(0.569 ; 0.693)$ & $<0.001$ \\
\hline Greatest decrease of $\mathrm{SpO}_{2}(\%)$ & $0.610(0.548 ; 0.67 I)$ & 0.001 \\
\hline
\end{tabular}

Notes: Receiver operating characteristic analysis was used to determine parameter ability to predict mortality of COPD patients. AUC with p-value illustrated the power of this ability. Significant differences are indicated in bold.

Abbreviations: 6-MWT, 6-minute walking test; $\mathrm{AUC}$, area under curve; $\mathrm{PaCO}_{2}$, partial pressure of arterial carbon dioxide; $\mathrm{PaO}_{2}$, partial pressure of arterial oxygen; $\mathrm{SpO}_{2}$, peripheral capillary oxygen saturation. with increased mortality in the complete cohort $(p=0.004)$ and in the GOLD 2017 B category ( $p=0.022)$. Desaturation was not associated with higher mortality in the GOLD 2017 D category $(p=0.175$; Figure $4 \mathrm{~A}-\mathrm{C})$.

\section{Univariate analyses}

Univariate analyses using the Cox model of proportional risk showed that different levels of oxemia and capnemia along with desaturation during a 6-MWT were risk factors for mortality in the complete cohort (Table 5A) as well as in the GOLD 2017 group B (Table 5B). In contrast, we found no relationship between the tested parameters and mortality risk in the GOLD $2017 \mathrm{D}$ category. Severe hypoxemia $\left(\mathrm{PaO}_{2}<7.3 \mathrm{kPa}\right)$ has been identified as a strong predictor of all-cause mortality in the complete cohort (hazard ratio [HR] 3.064; $p<0.001$ ) as well as in the GOLD 2017 B category (HR 3.532; $p=0.001$ ). Similarly, severe hypercapnia $\left(\mathrm{PaCO}_{2}>7 \mathrm{kPa}\right)$ has been identified as a strong predictor of all-cause mortality in the GOLD B category (HR 10.185; $p=0.001$ ). Blood $\mathrm{pH}$ was not associated with increased risk of death in any of the tested patient groups.

\section{Multivariate analyses}

A multivariate analysis containing patients with $\mathrm{PaO}_{2} \leq 7.3$ $\mathrm{kPa}$ identified $\mathrm{PaO}_{2} \leq 7.3 \mathrm{kPa}$ as a single and very strong independent risk factor for all-cause, long-term mortality 

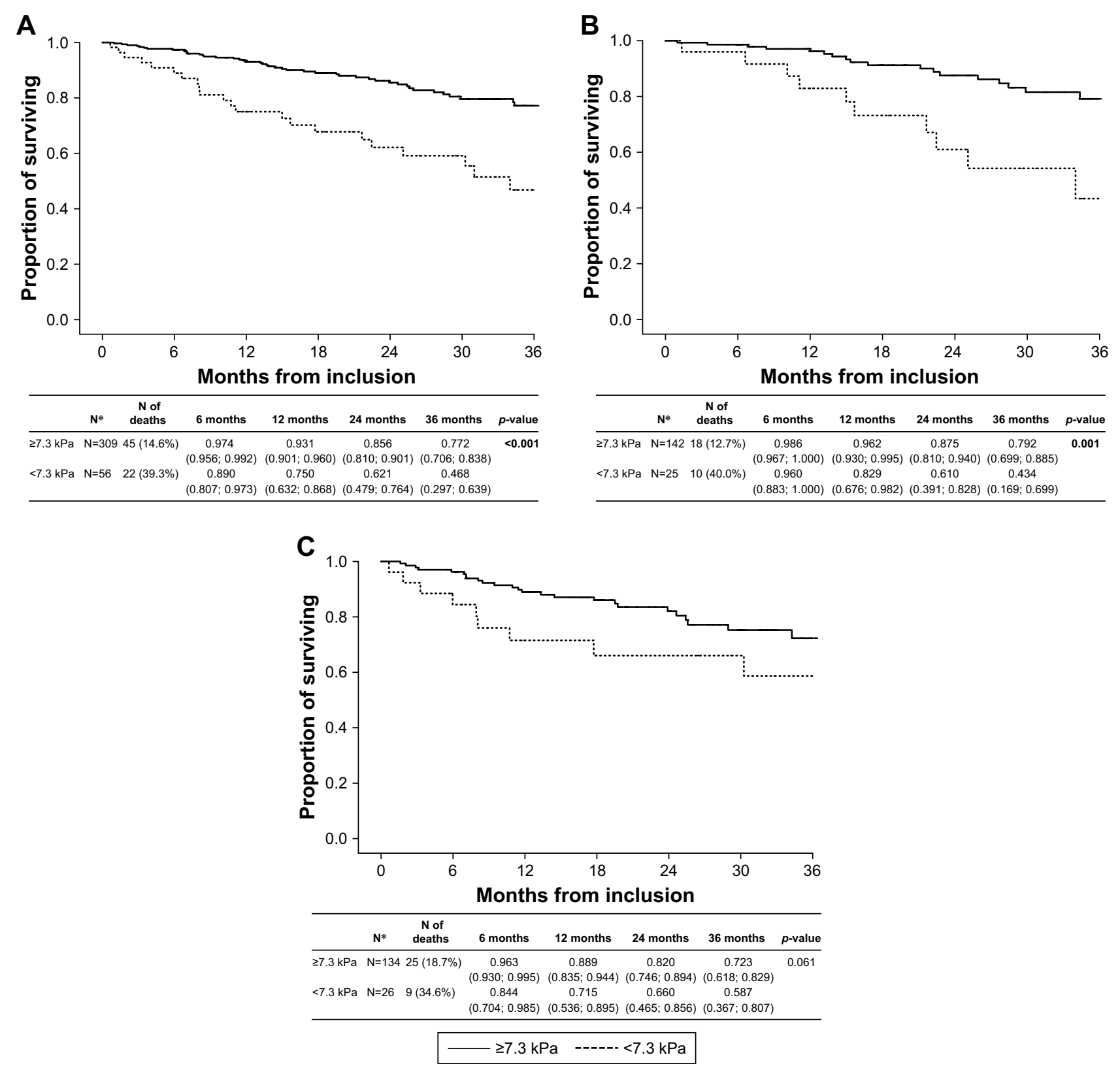

Figure 2 (A) Long-term survival according to $\mathrm{PaO}_{2}$ (all patients); (B) long-term survival according to PaO 2 (GOLD 2017 group B COPD subjects); (C) long-term survival according to $\mathrm{PaO}_{2}$ (GOLD 2017 group D COPD subjects).

Notes: *Number of patients with known follow-up. $p$-values $<0.001,0.001$ respectively in bold represent significant survival difference between presence of severe hypoxemia and absence of severe hypoxemia in total COPD cohort, and in GOLD 2017 B category.

Abbreviations: GOLD, Global Initiative for Obstructive Lung Disease; $\mathrm{PaCO}_{2}$, partial pressure of arterial carbon dioxide.

(HR 2.398; 95\% CI: 1.245-4.630) (Table 6). In an analysis containing three $\mathrm{PaCO}_{2}$ categories $(<5,5-7$ and $>7 \mathrm{kPa})$, none of the tested parameters showed as a significant, independent predictor of death (Table S2A). In a multivariate analysis containing desaturation during 6-MWT, only the BODE index was identified as an independent risk factor for all-cause mortality with HR 1.310 (95\% CI: 1.168-1.470) (Table S2B).

Additional note: When ideal cutoff values for each of the studied parameter were calculated, $\mathrm{PaO}_{2}$ level $<7.1 \mathrm{kPa}$ yielded the highest sensitivity and specificity. By using the
$\mathrm{PaO}_{2}$ level $<7.1 \mathrm{kPa}$ for a multivariate analysis, the $\mathrm{HR}$ of this independent risk factor was as high as 5.135 (95\% CI: 2.415-10.917) (Table S2C and D). However, oxemia levels of 7.3 and $8.0 \mathrm{kPa}$ are more relevant for clinicians; therefore, only these are further discussed in the paper.

\section{Additional analyses: assessment of the role of comorbidities}

The relationships between comorbidities and respiratory parameters in the CMRD study were also assessed 


\section{A}

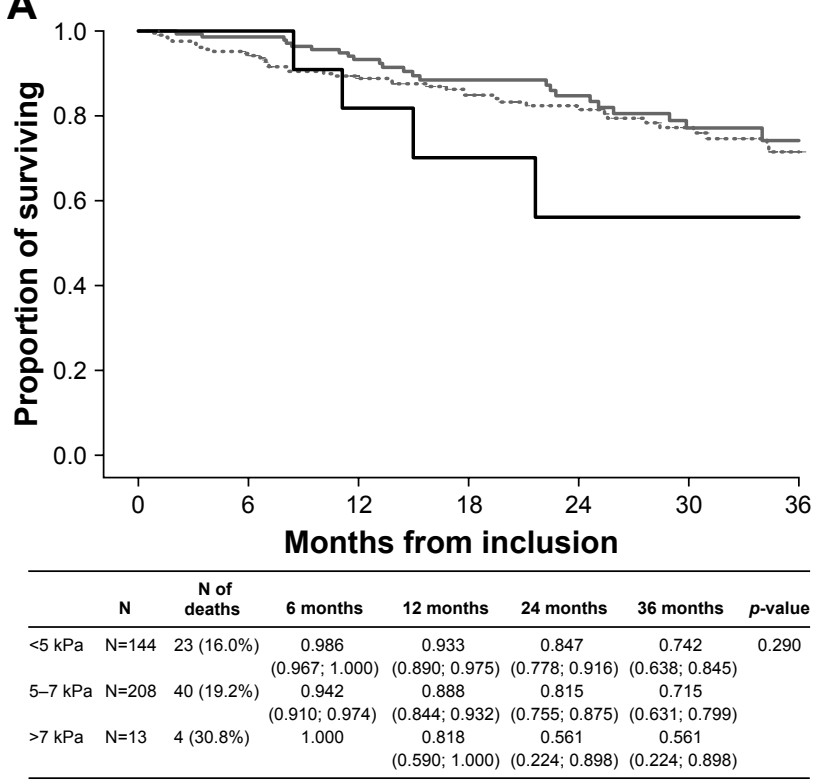

B

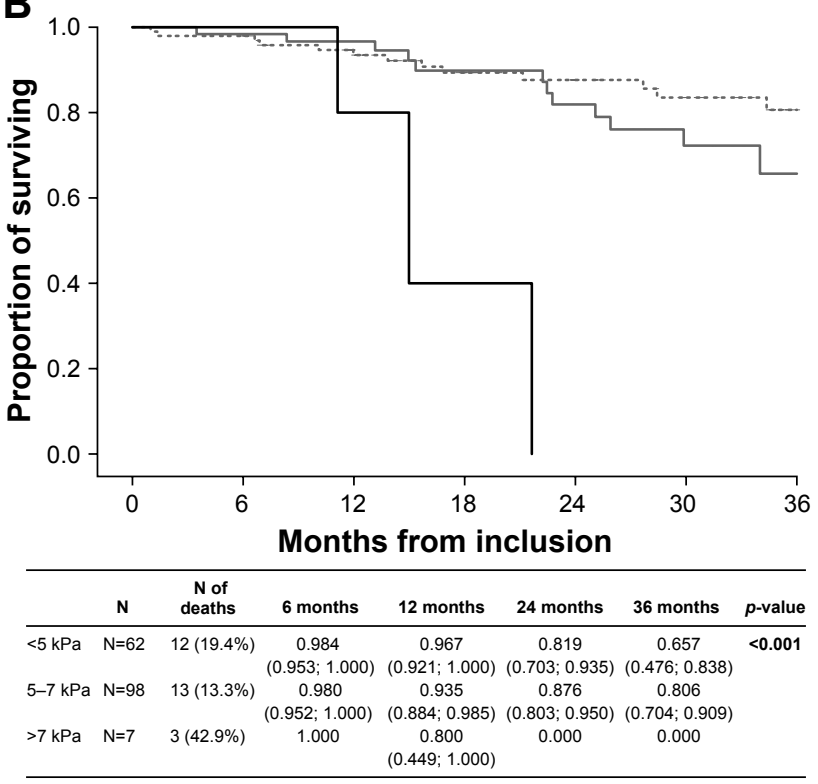

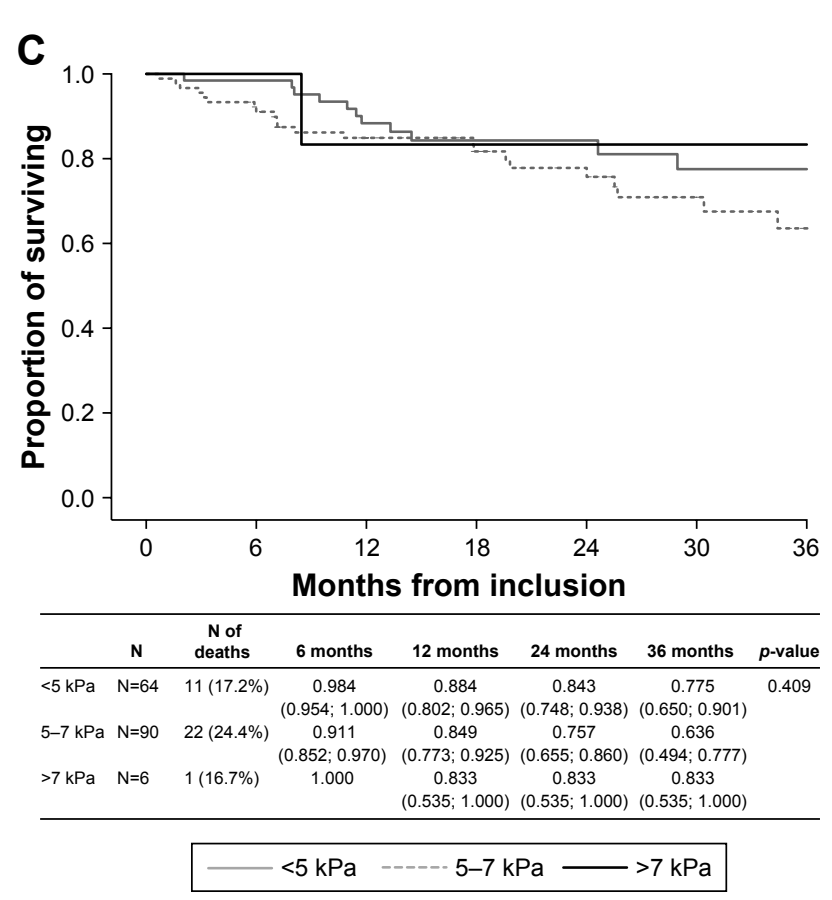

Figure 3 (A) Long-term survival according to $\mathrm{PaCO}_{2}$ (all patients); (B) long-term survival according to $\mathrm{PaCO}_{2}$ (GOLD 2017 group $\mathrm{B}$ COPD subjects); (C) long-term survival according to $\mathrm{PaCO}_{2}$ (GOLD 2017 group D COPD subjects).

Note: $p$-value $<0.00$ I in bold represents significant survival difference between hypocapnic, normocapnic, and hypercapnic patients in GOLD 2017 B category only. Abbreviations: GOLD, Global Initiative for Obstructive Lung Disease; $\mathrm{PaCO}_{2}$, partial pressure of arterial carbon dioxide.

(as complementary analyses). The self-reported history of heart failure, tumor and depression was associated with a greater probability of death during 3 years of follow-up (Table S3A). The presence of atopy was associated with higher levels of $\mathrm{PaO}_{2}$ (Table S3B). Personal history of heart failure, coronary artery disease and diabetes was associated with significantly lower $\mathrm{PaO}_{2}$ levels. Finally, levels of $\mathrm{PaCO}_{2}>$ or $<5-7 \mathrm{kPa}$ were associated with atopy and/or bronchial asthma, heart failure and/or diabetes (Table S3C).

\section{Discussion}

The most important finding of our study was that chronic hypoxemia $\left(\mathrm{PaO}_{2}<7.3 \mathrm{kPa}\right)$ was a distinctive and very strong prognosis-modifying pattern associated with increased risk of long-term mortality in COPD group B patients. We observed significant differences in all-cause long-term mortality supported by results from univariate and multivariate analyses in the complete cohort and in groups B and D (GOLD 2017). However, the association was the strongest for 

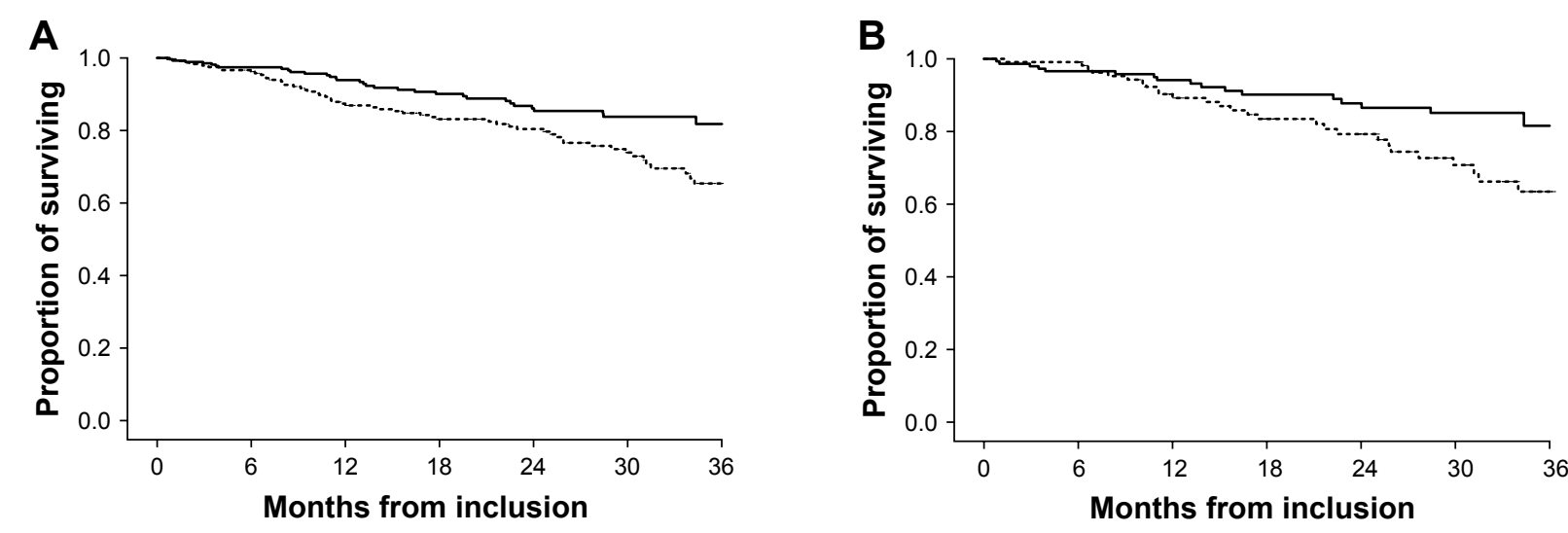

\begin{tabular}{cccccccc}
\hline & $\mathbf{N} *$ & $\begin{array}{c}\mathbf{N} \text { of } \\
\text { deaths }\end{array}$ & $\mathbf{6}$ months & $\mathbf{1 2}$ months & $\mathbf{2 4}$ months & $\mathbf{3 6}$ months & $\boldsymbol{p}$-value \\
\hline No & $\mathrm{N}=273$ & $32(11.7 \%)$ & 0.974 & 0.939 & 0.861 & 0.818 & $\mathbf{0 . 0 0 4}$ \\
& & & $(0.956 ; 0.993)$ & $(0.909 ; 0.969)$ & $(0.811 ; 0.910)$ & $(0.752 ; 0.884)$ & \\
\multirow{2}{*}{ Yes } & $\mathrm{N}=239$ & $55(23.0 \%)$ & 0.962 & 0.869 & 0.804 & 0.654 & \\
& & & $(0.938 ; 0.986)$ & $(0.824 ; 0.914)$ & $(0.749 ; 0.860)$ & $(0.570 ; 0.738)$ & \\
\hline
\end{tabular}

\begin{tabular}{cccccccc}
\hline & $\mathbf{N} *$ & $\begin{array}{c}\text { N of } \\
\text { deaths }\end{array}$ & $\mathbf{6}$ months & 12 months & 24 months & 36 months & p-value \\
\hline No & $\mathrm{N}=147$ & $17(11.6 \%)$ & 0.966 & 0.941 & 0.878 & 0.816 & $\mathbf{0 . 0 2 2}$ \\
& & & $(0.937 ; 0.995)$ & $(0.902 ; 0.981)$ & $(0.816 ; 0.939)$ & $(0.720 ; 0.911)$ & \\
Yes & $\mathrm{N}=112$ & $27(24.1 \%)$ & 0.991 & 0.892 & 0.793 & 0.635 & \\
& & & $(0.974 ; 1.000)$ & $(0.832 ; 0.953)$ & $(0.708 ; 0.877)$ & $(0.513 ; 0.756)$ & \\
\hline
\end{tabular}

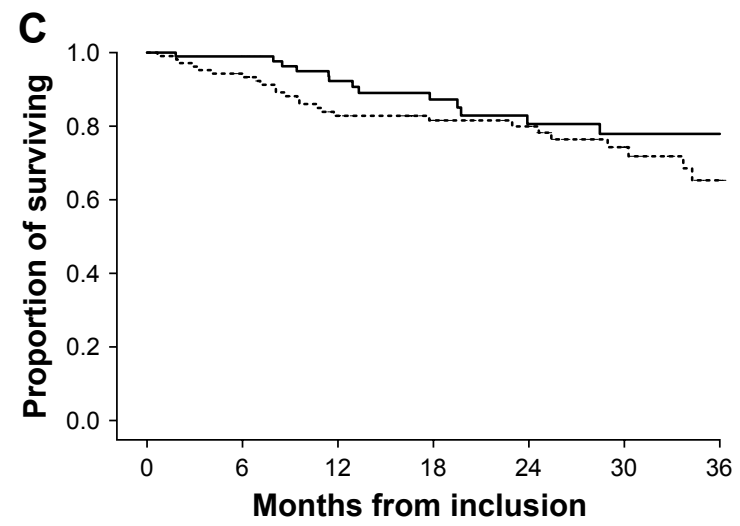

\begin{tabular}{|c|c|c|c|c|c|c|c|}
\hline & $\mathrm{N}^{*}$ & $\mathrm{~N}$ of deaths & 6 months & 12 months & 24 months & 36 months & $p$-value \\
\hline No & $\mathrm{N}=96$ & $13(13.5 \%)$ & $\begin{array}{c}0.990 \\
(0.969 ; 1.000)\end{array}$ & $\begin{array}{c}0.923 \\
(0.863 ; 0.982)\end{array}$ & $\begin{array}{c}0.806 \\
(0.703 ; 0.909)\end{array}$ & $\begin{array}{c}0.779 \\
(0.667 ; 0.891)\end{array}$ & 0.175 \\
\hline Yes & $\mathrm{N}=105$ & $25(23.8 \%)$ & $\begin{array}{c}0.933 \\
(0.885 ; 0.981)\end{array}$ & $\begin{array}{c}0.828 \\
(0.754 ; 0.903)\end{array}$ & $\begin{array}{c}0.799 \\
(0.717 ; 0.882)\end{array}$ & $\begin{array}{c}0.653 \\
(0.523 ; 0.782)\end{array}$ & \\
\hline
\end{tabular}

Figure 4 (A) Long-term survival according to desaturation (all patients); (B) long-term survival according to desaturation (GOLD 2017 group B COPD subjects); (C) longterm survival according to desaturation (GOLD 2017 group D COPD subjects).

Notes: *Number of patients with known follow-up. p-values $0.004,0.022$ respectively in bold represent significant survival difference between presence of desaturation and absence of desaturation in total COPD cohort, and in GOLD 2017 B category.

Abbreviation: GOLD, Global Initiative for Obstructive Lung Disease.

COPD group B. This finding is very important for clinicians because group B currently represents the largest portion of COPD patients in real-life studies. ${ }^{2}$ For this group, novel and easy-to-obtain parameters predictive of poor outcome are warranted. In our study, oxemia $<7.3 \mathrm{kPa}$ was the strongest independent predictor of mortality in COPD group B patients (using the GOLD 2017 Update). Where arterial blood gasometry is not available, desaturation during a 6-MWT - as an easier-to-obtain parameter (or a simple screening method) may be used instead of ABG analysis, according to our results. This finding might be important in emergency cases or within areas where ABG analyzers are unavailable.
Our study cohort comprised $71.7 \%$ men; median age was 67.1 years, median $\mathrm{FEV}_{1}$ was $46 \%$ pred and median $\mathrm{PaO}_{2}$ was $8.8 \mathrm{kPa}$. Compared to other large cohorts (ECLIPSE, POPE, COPDGene, COCOMICS), the main differences were lower $\mathrm{FEV}_{1}$ and lower proportion of group A patients in favor of groups B and D. ${ }^{14,15}$ Moreover, a greater proportion of men were enrolled in our study cohort. The differences in rates of COPD groups A-D along with lower median $\mathrm{FEV}_{1}$ are consequences of different inclusion criteria for enrolment in the CMRD study; only patients with $\mathrm{FEV}_{1} \leq 60 \%$ pred were included. ${ }^{13}$ The CMRD study is focused on all-cause long-term mortality of COPD patients. Patients with a more 
Table 5A Prediction of all-cause mortality by respiratory parameters - all patients

\begin{tabular}{|c|c|c|}
\hline \multirow{2}{*}{$\begin{array}{l}\text { Respiratory } \\
\text { parameter }\end{array}$} & \multicolumn{2}{|c|}{ Cox model of proportional risk } \\
\hline & HR (95\% CI) & $p$-value \\
\hline \multicolumn{3}{|l|}{$\mathrm{PaO}_{2}(\mathrm{kPa})$} \\
\hline Continuously* & $1.304(1.108-1.534)$ & 0.001 \\
\hline$<7.3$ & $3.064(1.840-5.103)$ & $<0.001$ \\
\hline$<8.0$ & 1.700 (I.040-2.779) & 0.034 \\
\hline \multicolumn{3}{|l|}{$\mathrm{PaCO}_{2}(\mathrm{kPa})$} \\
\hline Continuously** & I.484 (I.I77-I.870) & 0.001 \\
\hline $5.0-7.0$ & Reference category & \\
\hline$<5.0$ & $0.805(0.482-1.345)$ & 0.407 \\
\hline$>7.0$ & I.8I3 (0.648-5.07I) & 0.257 \\
\hline \multicolumn{3}{|l|}{ Desaturation } \\
\hline Yes & $1.883(1.217-2.911)$ & 0.004 \\
\hline
\end{tabular}

Notes: *HR represents change of risk of mortality, if parameter decreases by unit (lower values are risk). **HR represents change of risk of mortality, if parameter increases by unit (higher values are risk). Desaturation, greatest decrease of $\mathrm{SpO}_{2}$ during $6-\mathrm{MWT}(\%)>4 \%$ and/or minimal $\mathrm{SpO}_{2}$ during (after) 6-MWT (\%) $<90 \%$. p-values in bold represent significant change of mortality risk (expressed as hazard ratio). Abbreviations: 6-MWT, 6-minute walking test; $\mathrm{HR}$, hazard ratio; $\mathrm{PaCO}_{2}$, partial pressure of arterial carbon dioxide; $\mathrm{PaO}_{2}$, partial pressure of arterial oxygen; $\mathrm{SpO}_{2}$, peripheral capillary oxygen saturation.

pronounced impairment of lung function $\left(\mathrm{FEV}_{1} \leq 60 \%\right.$ pred $)$ are at higher risk of death compared to patients with mild COPD. All 14 centers of the CMRD project represent university or tertiary-type hospitals taking care of nonmild COPD patients. ${ }^{13}$ In addition, the absence of COPD patients with $\mathrm{FEV}_{1}>60 \%$ reduces the chance of mistaken enrolment of patients with transient, mild bronchial obstruction (eg, smoking asthmatics who can normalize lung function within a few months). Moreover, globally, milder COPD patients are often underdiagnosed. ${ }^{2,13}$ On the other hand, the $\mathrm{FEV}_{1}$ threshold in the CMRD study set at $60 \%$ pred

Table 5B Prediction of all-cause mortality by respiratory parameters - GOLD 2017 B patients

\begin{tabular}{|c|c|c|}
\hline & \multicolumn{2}{|c|}{ Cox model of proportional risk } \\
\hline & HR (95\% Cl) & $p$-value \\
\hline \multicolumn{3}{|l|}{$\mathrm{PaO}_{2}(\mathrm{kPa})$} \\
\hline Continuously* & $1.282(0.997-1.647)$ & 0.052 \\
\hline$<7.3$ & $3.532(1.628-7.662)$ & 0.001 \\
\hline$<8.0$ & $1.462(0.675-3.169)$ & 0.336 \\
\hline \multicolumn{3}{|l|}{$\mathrm{PaCO}_{2}(\mathrm{kPa})$} \\
\hline Continuously** & $1.723(1.085-2.734)$ & 0.021 \\
\hline $5.0-7.0$ & Reference category & \\
\hline$<5.0$ & $1.564(0.7 \mid 2-3.438)$ & 0.265 \\
\hline$>7.0$ & $10.185(2.719-38.158)$ & 0.001 \\
\hline \multicolumn{3}{|l|}{ Desaturation } \\
\hline Yes & 2.001 (1.090-3.672) & 0.025 \\
\hline
\end{tabular}

Notes: *HR represents change of risk of mortality, if parameter decreases by unit (lower values are risk). **HR represents change of risk of mortality, if parameter increases by unit (highervalues are risk). Desaturation, greatest decrease of $\mathrm{SpO}_{2}$ during $6-\mathrm{MWT}(\%)>4 \%$ and/or minimal $\mathrm{SpO}_{2}$ during (after) 6-MWT (\%) $<90 \%$. p-values in bold represent significant change of mortality risk (expressed as hazard ratio).

Abbreviations: 6-MWT, 6-minute walking test; $\mathrm{HR}$, hazard ratio; $\mathrm{PaCO}_{2}$, partial pressure of arterial carbon dioxide; $\mathrm{PaO}_{2}$, partial pressure of arterial oxygen; $\mathrm{SpO}_{2}$, peripheral capillary oxygen saturation.
Table 6 Prediction of all-cause mortality - multivariate analysis containing $\mathrm{PaO}_{2}(\mathrm{kPa}) \leq 7.3$

\begin{tabular}{lll}
\hline $\begin{array}{l}\text { Prognostic } \\
\text { parameter }\end{array}$ & \multicolumn{2}{l}{ Cox model of proportional risk } \\
\cline { 2 - 3 } & HR $(\mathbf{9 5 \%} \mathrm{Cl})$ & p-value \\
\hline $6-\mathrm{MWD}(\mathrm{m}) *$ & $0.996(0.993-0.999)$ & $\mathbf{0 . 0 0 3}$ \\
$\mathrm{PaO}_{2}(\mathrm{kPa}) \leq \mathbf{7 . 3}$ & $2.398(1.245-4.630)$ & $\mathbf{0 . 0 0 9}$ \\
\hline
\end{tabular}

Notes: $* H R$ represents change of risk of mortality, if parameter increases by unit. $p$-values in bold represent significant change of mortality risk (expressed as hazard ratio).

Abbreviations: 6-MWD, 6-minute walking distance; $\mathrm{HR}$, hazard ratio; $\mathrm{PaO}_{2}$, partial pressure of arterial oxygen.

allowed us to analyze also a substantial portion of GOLD stage 2 patients, not just GOLD stage 3 and 4 subjects. Thus, we believe that the CMRD study cohort (including GOLD stage 2-4 individuals) is representative of a real-life setting. The low number of patients and of deaths in groups $\mathrm{A}$ and $\mathrm{C}$ (resulting from the abovementioned facts) did not allow us to perform mortality analyses for these groups.

The proportions of GOLD categories (groups) in our study cohort were represented as follows: groups A+C $10.2 \%$, group B 20.2\% and group D 69.6\% when GOLD 2016 classification was used. Application of the GOLD 2017 Update resulted in major shifts in the distribution of patients across A-D groups, that is, groups A+C $10.2 \%$ and group D $36.7 \%$, whereas group B, at $53.0 \%$, represented the most numerous disease category in our cohort. Similar results were published recently by Tudoric et al and Koblizek et al, who demonstrated the consequences of application of the GOLD 2017 Update on the POPE study population, comprising 3,361 COPD patients. ${ }^{2,15}$ The authors observed major shifts in the distribution of COPD groups A-D, resulting in making group B the most abundant. According to the GOLD 2016 guideline, group B was represented in $30.5 \%$ and group D in $57.3 \%{ }^{2,15}$ When applying the classification approach presented in the GOLD 2017 Update, 50.8\% of patients were classified in B and $36.9 \%$ in group D. ${ }^{2,15}$ Importantly, the authors pointed out that $71.5 \%$ of the patients who shifted from group D to B used inhaled corticosteroids (ICS), and $18.4 \%$ of these group D-to-B shifters had severe airflow limitation (GOLD 4). In consequence, the shift to stage $\mathrm{B}$ in these patients may result in discontinuation of ICS treatment and/or in reduction of dual bronchodilator therapy to single bronchodilator use with potentially harmful consequences (ie, unstable COPD and risk of disease progression). ${ }^{2}$ The authors concluded that the GOLD 2017 Update is relatively closer to the phenotypic approach in the disease management. ${ }^{2}$ However, the abovementioned shortcomings of the GOLD 2017 Update stress the need for identifying group B patients at higher risk of rapid disease progression and poor outcome.

Our data showed that a negative correlation exists among $\mathrm{PaO}_{2}$, basal $\mathrm{SpO}_{2}$ and minimal $\mathrm{SpO}_{2}$ on the one hand and 
$\mathrm{PaCO}_{2}$ on the other hand. This finding is in accordance with the differences in pathophysiology of both types of respiratory failure. Interestingly, some patients with the same disease develop only hypoxemia, whereas others also develop hypercapnia. Hypercapnia alone is rather a rare condition in the COPD population. Although both types of respiratory failure may coexist in a single patient (with increased probability in certain diseases, eg, in COPD patients), the underlying mechanisms of development of hypoxemia and hypercapnia exhibit differences. Hypercapnia is the respiratory expression of alveolar hypoventilation, and in COPD, it results dominantly from severe airflow limitation and hyperinflation. ${ }^{16}$ Hypercapnia and respiratory acidosis may augment the decrease in respiratory muscle function because of the deleterious effect on mitochondrial function. ${ }^{16}$ The most important mechanisms underlying the development of chronic hypoxemia include ventilatory/respiratory mismatch, right-to-left shunt, decreased/impaired diffusion, alveolar hypoventilation and hypoxia due to low oxygen intake. ${ }^{11,17}$ Hypoxemia increases ventilatory drive to increase $\mathrm{PaO}_{2}$ (thus decreasing $\mathrm{PaCO}_{2}$ ), induces regional pulmonary vasoconstriction and peripheral vasodilation (thus increasing heart rate and cardiac output) and stimulates erythropoiesis, resulting in enhanced oxygen-transporting capacity, although the hematologic viscosity rises. ${ }^{18}$ In consequence, breathing becomes more difficult, and the cardiac workload increases. ${ }^{18}$

In COPD patients, by far the most important determinant of hypoxemia is ventilatory/respiratory mismatch (V/Q mismatch). ${ }^{11,18} \mathrm{~V} / \mathrm{Q}$ mismatch is the consequence of hypoxic pulmonary vasoconstriction that develops in areas with reduced ventilation (eg, emphysema). ${ }^{11}$ In the COPDGene study, female sex, higher BMI and reduced $\mathrm{FEV}_{1}$ were associated with the development of chronic hypoxemia in COPD patients. ${ }^{19}$

As demonstrated in our study, chronic hypoxemia is a major risk factor for mortality in COPD patients. Several other studies showed similar results. ${ }^{20-22}$ The severity of chronic hypoxemia is strengthened by the fact that longterm oxygen treatment (LTOT) may not decrease mortality in mild-to-moderate hypoxemic COPD patients. ${ }^{23,24}$ In the CMRD study, almost $11 \%$ of the included COPD individuals (78 out of 725) were treated with LTOT. The evidence for indication of LTOT is traditionally based on the results of three studies conducted in the $1970 \mathrm{~s} .{ }^{25-27}$ Recent research confirms that LTOT in stable COPD patients with moderate desaturation (ie, with mild-to-moderate chronic respiratory failure) does not provide any substantial benefit in relation to mortality, time to first hospitalization or any other followed endpoint. ${ }^{24}$ However, for COPD patients with severe chronic hypoxemia, LTOT significantly reduces long-term mortality and remains one of the most important treatment options. ${ }^{20}$ In a systematic review of randomized trials, no mortality benefit was observed if hypoxemia was present because of cause other than COPD or cardiogenic pulmonary edema. ${ }^{28}$ Our results showed positive correlation between basal $\mathrm{SpO}_{2}$, minimal $\mathrm{SpO}_{2}$ and hypoxemia. The relationships between $\mathrm{PaO}_{2}$ and $\mathrm{SpO}_{2}$ were assessed in a Spanish study published in 2015. ${ }^{29}$ The authors demonstrated that in patients with acute exacerbation of COPD (AE-COPD), $\mathrm{SpO}_{2}$ had a high correlation coefficient with $\mathrm{PaO}_{2}(0.89)$, and the optimal cutoff value for the detection of hypoxemia was $\mathrm{SpO}_{2} 90 \%{ }^{29}$

In our study, hypercapnia $>7 \mathrm{kPa}$ was predictive of poor outcome in Kaplan-Meier survival analyses and in univariate analyses. However, in multivariate analyses, $\mathrm{PaCO}_{2}$ failed to be an independent risk factor. These findings are in accordance with previous research. The prognostic value of carbon dioxide in the blood and hypercapnia were much weaker than that of hypoxemia in relation to mortality. Jones et al reported $\mathrm{PaCO}_{2}$ to be a significant predictor of long-term mortality in COPD patients..$^{30}$ Foucher et al reported $30 \%-40 \%$ twoyear mortality of COPD patients with chronic hypercapnia. ${ }^{31}$ Chailleux et al found hypercapnia associated with higher mortality in COPD patients receiving LTOT at the 3-year follow-up..$^{32}$ Ahmadi et al referred to the U-shaped association between capnemia and mortality, with values $>7.0$ and $<5.0$ $\mathrm{kPa}$ at increased risk of death. ${ }^{27}$ However, Aida et al found no association between capnemia and mortality. ${ }^{33}$

Research data supporting the prognostic value of capnemia are more consistent for acute hypercapnia. ${ }^{12,34-36}$ Lun et al reported association between hypercapnia and respiratory acidosis during AE-COPD with higher risk of future lifethreatening events and mortality. ${ }^{12}$ Acute hypercapnia during AE-COPD has been found as a significant prognostic factor of long-term mortality in a number of studies..$^{34-36}$

In COPD patients with chronic respiratory failure, acute respiratory failure is the most common cause of death, followed by cardiovascular causes, respiratory infection and cancer. ${ }^{3,37,38}$ Acute respiratory failure is frequently associated with exacerbations (and vice versa).$^{38}$ In-hospital mortality of patients with AE-COPD and acute respiratory failure was only $2.5 \%$ in a cohort examined by Patil et al, ${ }^{39}$ but $20.3 \%$ in a study by Breen et al. ${ }^{40}$ In the same study, postdischarge mortality at 3 years was $63.5 \% .^{40}$ In-hospital mortality of mechanically ventilated patients with acute respiratory failure ranges between $21 \%$ and $82 \%$, according to the results of various studies. ${ }^{41}$ The association between acute/ 
chronic respiratory failure and mortality applies despite the discovery of several prognosis-modifying treatments and strategies for COPD in the last decades, including ICS, ${ }^{42}$ their combination with long-acting bronchodilators ${ }^{43}$ or noninvasive ventilation. ${ }^{44}$ Considering the data obtained from the ECLAIR study, extracorporeal carbon dioxide removal for acute hypercapnic respiratory failure has been found to be neither an effective nor a safe procedure. ${ }^{45}$

Our study has several limitations. The first one is the preselection bias caused by inclusion of patients with postbronchodilator $\mathrm{FEV}_{1} \leq 60 \%$ only. Seventy-two percent of the study population were men, which might introduce another bias (gender). In the study cohort, only a minimum (ca. $10 \%$ in total) of group A and group C patients were present. In consequence, the number of deaths for these groups was so low that it did not allow us to perform mortality analyses. Another important limitation is related to relatively lower availability of ABG (54\% of patients) and 6-MWT data (76\% of patients) from the CMRD study cohort. The primary aim of the CMRD study was to observe the rate of all-cause mortality in a real-life COPD population. Monitoring of respiratory parameters ( $\mathrm{ABG}$ and $\mathrm{SpO}_{2}$ during 6-MWT) was considered an additional and a nonmandatory component only. This might bias the composition of the current study cohort because more expressed impairment of lung function and more frequent hospitalization because of COPD exacerbation (before enrolment) might slightly increase the patient's chance of having ABG analysis. In contrast, better lung functions were associated with a gently higher frequency of 6-MWT being performed. According to our ex-post analysis, the differences between these groups were minimal (Table S4). Moreover, of the 725 enrolled subjects, $\mathrm{SpO}_{2}$ was measured during a mandatory physical exam and the results strongly correlated with $\mathrm{SpO}_{2}$ assessed during a 6-MWT (Table S5A and B).

Despite these limitations, we believe that we demonstrated the importance and the prognostic role of respiratory parameters, particularly of $\mathrm{PaO}_{2}<7.3 \mathrm{kPa}$ in COPD category B patients (GOLD 2017 Update).

\section{Conclusion}

Our results show that certain respiratory parameters are associated with increased risk of death among patients in different COPD categories. Of the tested parameters, severe hypoxemia $\left(\mathrm{PaO}_{2}<7.3 \mathrm{kPa}\right)$ was identified as the strongest risk factor for long-term, all-cause mortality in the complete cohort as well as in group B (using the GOLD 2017 Update). The importance of this finding is underlined by the fact that group B seems to be the largest group of COPD individuals in real practice. ${ }^{2}$ In emergency cases, $\mathrm{SpO}_{2}$ may be used to determine the presence of hypoxemia. Undoubtedly, for exact $\mathrm{PaO}_{2}$ measures, arterial blood gasometry should be performed.

Another important observation is that COPD category D (GOLD 2017 Update) now seems to be a well-defined group with the highest rate of long-term mortality and a minimum of risk-modifying signs and factors.

\section{Acknowledgments}

We thank the physicians of participating centers of the Czech multicenter research database of severe COPD, namely, Tomas Dvorak - Pulmonary Department, Hospital Mlada Boleslav, Petr Safranek - Pulmonary Department, University Hospital, Plzen, Ondrej Sobotik - Pulmonary Department, University Hospital Motol, Prague, Maria Majerciakova - Pulmonary Department, Hospital of St Svorad, Nitra, Slovakia, Jaroslav Lnenicka - Pulmonary Department, Masaryk Hospital, Usti nad Labem, Pavlina Musilova - Pulmonary Department, Jihlava Hospital, Barbora Novotna - Pulmonary Department, Bulovka Hospital, Prague, Zuzana Liptakova - Pulmonary Department, Ceske Budejovice Hospital, Eva Kocova, Michal Kopecky, Sarka Pracharova, Libor Nevoranek and Lukas Varhanik - University Hospital Hradec Kralove, Katerina Neumannova - Palacky University, Olomouc and Milada Sipkova - Pulmonary Department, Liberec Hospital. Special thanks to Ondrej Zindr - Karlovy Vary for English corrections. This research was funded by Ministry of Health of the Czech Republic (15/14/NAP, 5/15/NAP, and UHHK, 00179906), moreover by consortium of several pharmaceutical companies (Angelini CZ, AstraZeneca CZ, Boehringer Ingelheim CZ, Cipla CZ, CSL Behring CZ, GSK CZ, Novartis CZ and Sandoz CZ).

\section{Disclosure}

M Plutinsky has received payments on COPD lectures from Boehringer Ingelheim. P Popelkova has received consulting/ lectures payment from AstraZeneca, Boehringer Ingelheim and Novartis regarding the COPD field within past 36 months. J Zatloukal has received payment related to COPD clinical trials from AstraZeneca, GSK and Novartis within past 36 months, and received consulting/lectures payment from AstraZeneca, Novartis, Angelini and Berlin-Chemie regarding the COPD field within past 36 months. E Volakova has received COPD research funding from GSK within past 36 months, and received consulting/lectures payment from Boehringer Ingelheim and Berlin-Chemie regarding the COPD field within past 36 months. L Heribanová has 
received COPD research funding from AstraZeneca within past 36 months. V Koblizek has received COPD research funding from Boehringer Ingelheim, and Novartis within past 36 months, and received consulting/lectures payment from Angelini, AstraZeneca, Berlin-Chemie, Boehringer Ingelheim, GSK, Mundipharma, Novartis and Sandoz regarding the COPD field within past 36 months. K Brat, K Hejduk, M Svoboda and M Fecaninova have not received any payments within past 36 months. The authors report no other conflicts of interest in this work.

\section{References}

1. Global Strategy for the Diagnosis, Management and Prevention of COPD, Global Initiative for Chronic Obstructive Lung Disease (GOLD); 2017. Available from: http://goldcopd.org. Accessed May 30, 2017.

2. Tudoric N, Koblizek V, Miravitlles M, et al. GOLD 2017 on the way to a phenotypic approach? Analysis from the Phenotypes of COPD in Central and Eastern Europe (POPE) Cohort. Eur Respir J. 2017; 49(4): 1602518.

3. Sin DD, Anthonisen NR, Soriano JB, Agusti AG. Mortality in COPD: role of comorbidities. Eur Respir J. 2006;28(6):1245-1257.

4. de Torres JP, Casanova C, Marín JM, et al. Prognostic evaluation of COPD patients: GOLD 2011 versus BODE and the COPD comorbidity index COTE. Thorax. 2014;69(9):799-804.

5. Celli BR, Cote CG, Marin JM, et al. The body-mass index, airflow obstruction, dyspnea, and exercise capacity index in chronic obstructive pulmonary disease. $N$ Engl J Med. 2004;350(10):1005-1012.

6. Steer J, Gibson GJ, Bourke SC. Predicting outcomes following hospitalization for acute exacerbations of COPD. QJM. 2010;103(11): $817-829$.

7. Sundh J, Janson C, Lisspers K, Montgomery S, Ställberg B. Clinical COPD Questionnaire score (CCQ) and mortality. Int J Chron Obstruct Pulmon Dis. 2012;7:833-842.

8. Global Strategy for Diagnosis, Management, and Prevention of COPD; 2016. Available from: http://goldcopd.org. Accessed May 30, 2017.

9. Agusti A, Edwards LD, Celli B; for ECLIPSE Investigators. Characteristics, stability and outcomes of the 2011 GOLD COPD groups in the ECLIPSE cohort. Eur Respir J. 2013;42(3):636-646.

10. Lange P, Marott JL, Vestbo J, et al. Prediction of the clinical course of chronic obstructive pulmonary disease, using the new GOLD classification: a study of the general population. Am J Respir Crit Care Med. 2012;186(10):975-981.

11. Sarkar M, Niranjan N, Banyal PK. Mechanisms of hypoxemia. Lung India. 2017;34(1):47-60.

12. Lun CT, Tsui MS, Cheng SL, et al. Differences in baseline factors and survival between normocapnia, compensated respiratory acidosis and decompensated respiratory acidosis in COPD exacerbation: a pilot study. Respirology. 2016;21(1):128-136.

13. Novotna B, Koblizek V, Zatloukal J, et al. Czech multicenter research database of severe COPD. Int J Chron Obstruct Pulmon Dis. 2014;9: $1265-1274$.

14. Agusti A, Hurd S, Jones P, et al. FAQs about the GOLD 2011 assessment proposal of COPD: a comparative analysis of four different cohorts. Eur Respir J. 2013;42(5):1391-1401.

15. Koblizek V, Milenkovic B, Barczyk A, et al. Phenotypes of COPD patients with a smoking history in Central and Eastern Europe: the POPE Study. Eur Respir J. 2017;49(5):1601446.

16. Slenter RH, Sprooten RT, Kotz D, Wesseling G, Wouters EF, Rohde GG. Predictors of 1-year mortality at hospital admission for acute exacerbations of chronic obstructive pulmonary disease. Respiration. 2013;85(1):15-26.
17. Panos RJ, Eschenbacher W. Exertional desaturation in patients with chronic obstructive pulmonary disease. COPD. 2009;6(6):478-487.

18. Corrado A, Renda T, Bertini S. Long-term oxygen therapy in COPD: evidences and open questions of current indications. Monaldi Arch Chest Dis. 2010;73(1):34-43.

19. Kim DK, Jacobson FL, Washko GR, et al. Clinical and radiographic correlates of hypoxemia and oxygen therapy in the COPDGene study. Respir Med. 2011;105(8):1211-1221.

20. Kim V, Benditt JO, Wise RA, Sharafkhaneh A. Oxygen therapy in chronic obstructive pulmonary disease. Proc Am Thorac Soc. 2008;5(4): 513-518.

21. Kent BD, Mitchell PD, McNicholas WT. Hypoxemia in patients with COPD: cause, effects, and disease progression. Int J Chron Obstruct Pulmon Dis. 2011;6:199-208.

22. Aanerud M, Saure EW, Benet M, et al. Serial measurements of arterial oxygen tension are associated with mortality in COPD. COPD. 2015; 12(3):287-294.

23. Górecka D, Gorzelak K, Sliwiński P, Tobiasz M, Zieliński J. Effect of long-term oxygen therapy on survival in patients with chronic obstructive pulmonary disease with moderate hypoxaemia. Thorax. 1997; 52(8):674-679.

24. Albert RK, Au DH, Blackford AL; for Long-Term Oxygen Treatment Trial Research Group. A randomized trial of long-term oxygen for COPD with moderate desaturation. N Engl J Med. 2016;375(17):1617-1627.

25. Continuous or nocturnal oxygen therapy in hypoxemic chronic obstructive lung disease: a clinical trial. Nocturnal Oxygen Therapy Trial Group. Ann Intern Med. 1980;93(3):391-398.

26. Long term domiciliary oxygen therapy in chronic hypoxic cor pulmonale complicating chronic bronchitis and emphysema. Report of the Medical Research Council Working Party. Lancet. 1981;1(8222):681-686.

27. Ahmadi Z, Bornefalk-Hermansson A, Franklin KA, Midgren B, Ekström MP. Hypo- and hypercapnia predict mortality in oxygendependent chronic obstructive pulmonary disease: a population-based prospective study. Respir Res. 2014;15:30.

28. Keenan SP, Sinuff T, Cook DJ, Hill NS. Does noninvasive positive pressure ventilation improve outcome in acute hypoxemic respiratory failure? A systematic review. Crit Care Med. 2004;32(12):2516-2523.

29. Garcia-Gutierrez S, Unzurrunzaga A, Arostegui I; for IRYSS-COPD group. The use of pulse oximetry to determine hypoxemia in acute exacerbations of COPD. COPD. 2015;12(6):613-620.

30. Jones NL, Burrows B, Fletcher CM. Serial studies of 100 patients with chronic airway obstruction in London and Chicago. Thorax. 1967; 22(4):327-335.

31. Foucher P, Baudouin N, Merati M, et al. Relative survival analysis of 252 patients with COPD receiving long-term oxygen therapy. Chest. 1998;113(6):1580-1587.

32. Chailleux E, Fauroux B, Binet F, Dautzenberg B, Polu JM. Predictors of survival in patients receiving domiciliary oxygen therapy or mechanical ventilation. A 10-year analysis of ANTADIR Observatory. Chest. 1996;109(3):741-749.

33. Aida A, Miyamoto K, Nishimura M, Aiba M, Kira S, Kawakami Y. Prognostic value of hypercapnia in patients with chronic respiratory failure during long-term oxygen therapy. Am J Respir Crit Care Med. 1998;158(1):188-193.

34. Ai-Ping C, Lee KH, Lim TK. In-hospital and 5-year mortality of patients treated in the ICU for acute exacerbation of COPD: a retrospective study. Chest. 2005;128(2):518-524.

35. Galli JA, Krahnke JS, James Mamary A, Shenoy K, Zhao H, Criner GJ. Home non-invasive ventilation use following acute hypercapnic respiratory failure in COPD. Respir Med. 2014;108(5):722-728.

36. Chu CM, Chan VL, Lin AW, Wong IW, Leung WS, Lai CK. Readmission rates and life threatening events in COPD survivors treated with non-invasive ventilation for acute hypercapnic respiratory failure. Thorax. 2004;59(12):1020-1025.

37. Zielinski J, MacNee W, Wedzicha J, et al. Causes of death in patients with COPD and chronic respiratory failure. Monaldi Arch Chest Dis. 1997;52(1):43-47. 
38. Vidal S, González N, Barrio I; for Investigación en Resultados y Servicios Sanitarios (IRYSS) COPD Group. Predictors of hospital admission in exacerbations of chronic obstructive pulmonary disease. Int J Tuberc Lung Dis. 2013;17(12):1632-1637.

39. Patil SP, Krishnan JA, Lechtzin N, Diette GB. In-hospital mortality following acute exacerbation of chronic obstructive pulmonary disease. Arch Int Med. 2003;163(10):1180-1186.

40. Breen D, Churches T, Hawker F, Torzillo PJ. Acute respiratory failure secondary to chronic obstructive pulmonary disease treated in the intensive care unit: a long term follow up study. Thorax. 2002;57(1): 29-33.

41. Nevins ML, Epstein SK. Predictors of outcome for patients with COPD requiring invasive mechanical ventilation. Chest. 2001;119(6): $1840-1849$.
42. Sin DD, Wu L, Anderson JA, et al. Inhaled corticosteroids and mortality in chronic obstructive pulmonary disease. Thorax. 2005;60(12):992-997.

43. Kliber A, Lynd LD, Sin DD. The effects of long-acting bronchodilators on total mortality in patients with stable chronic obstructive pulmonary disease. Respir Res. 2010;11:56.

44. Dretzke J, Blissett D, Dave C, et al. The cost-effectiveness of domiciliary non-invasive ventilation in patients with end-stage chronic obstructive pulmonary disease: a systematic review and economic evaluation. Health Technol Assess. 2015;19(81):1-246.

45. Braune S, Sieweke A, Brettner F, et al. The feasibility and safety of extracorporeal carbon dioxide removal to avoid intubation in patients with COPD unresponsive to noninvasive ventilation for acute hypercapnic respiratory failure (ECLAIR study): multicentre case-control study. Intensive Care Med. 2016;42(9):1437-1444. 


\section{Supplementary materials}

Table SI Frequency of desaturation $(n=552)$

\begin{tabular}{ll}
\hline Desaturation & $\mathbf{n = 5 5 2}$ \\
\hline No & $296(53.6 \%)$ \\
Yes & $256(46.4 \%)$ \\
\hline
\end{tabular}

Note: Desaturation means greatest decrease of $\mathrm{SpO}_{2}$ during 6-MWT (\%) $>4 \%$ and/or minimal $\mathrm{SpO}_{2}$ during (after) 6-MWT (\%) $<90 \%$.

Abbreviations: 6-MWT, 6-minute walking test; $\mathrm{SpO}_{2}$, basal peripheral capillary oxygen saturation.

Table S2 (A) Prediction of all-cause mortality - multivariate analysis containing $\mathrm{PaCO}_{2}(\mathrm{kPa})$ - categories $(<5 ; 5-7-$ reference; $>7)$. (B) Prediction of all-cause mortality - multivariate analysis containing desaturation. (C) Prediction of mortality by parameters of blood gases - ideal cutoff values. (D) Prediction of mortality - multivariate analysis containing $\mathrm{PaO}_{2}(\mathrm{kPa}) \leq 7.1$.

\begin{tabular}{|c|c|c|c|c|c|}
\hline \multirow[t]{2}{*}{ Prognostic parameter } & & \multicolumn{4}{|c|}{ Cox model of proportional risk } \\
\hline & & HR (95\% Cl) & & & $p$-value \\
\hline \multicolumn{6}{|l|}{$\mathbf{A}$} \\
\hline $\mathrm{TL}_{\mathrm{co}}(\%)^{*}$ & & $0.979(0.96 I-0.998)$ & & & 0.032 \\
\hline 6-MWD $(\mathrm{m})^{*}$ & & $0.996(0.993-0.998)$ & & & 0.001 \\
\hline $\mathrm{PaCO}_{2}(\mathrm{kPa})$ & & - & & & - \\
\hline \multicolumn{6}{|l|}{ B } \\
\hline BODE* & & $1.310(1.168-1.470)$ & & & $<0.001$ \\
\hline TLC (\%)* & & $0.985(0.975-0.995)$ & & & 0.004 \\
\hline \multirow[t]{2}{*}{ Desaturation } & & - & & & - \\
\hline & AUC (95\% CI) & $p$-value & Cutoff & Sensitivity & Specificity \\
\hline \multicolumn{6}{|l|}{ C } \\
\hline $\mathrm{PaO}_{2}(\mathrm{kPa})$ & $0.590(0.507 ; 0.673)$ & 0.020 & $\leq 7.1$ & 0.313 & 0.914 \\
\hline $\mathrm{PaCO}_{2}(\mathrm{kPa})$ & $0.600(0.521 ; 0.679)$ & 0.010 & $\geq 0.54$ & 0.537 & 0.654 \\
\hline Basal $\mathrm{SpO}_{2}(\%)$ & $0.607(0.537 ; 0.676)$ & 0.002 & $\leq 95.5$ & 0.701 & 0.473 \\
\hline Minimal $\mathrm{SpO}_{2}$ during 6-MWT (\%) & $0.631(0.569 ; 0.693)$ & $<0.00$ I & $\leq 93.5$ & 0.851 & 0.366 \\
\hline \multirow{3}{*}{ Greatest decrease in $\mathrm{SpO}_{2}(\%)$} & $0.610(0.548 ; 0.67 I)$ & $0.00 \mathrm{I}$ & $\geq 4.5$ & 0.552 & 0.626 \\
\hline & & \multicolumn{4}{|c|}{ Cox model of proportional risk } \\
\hline & & HR (95\% Cl) & & & $p$-value \\
\hline \multicolumn{6}{|l|}{ D } \\
\hline BMI* & & $0.921(0.865-0.982)$ & & & 0.012 \\
\hline $\mathrm{RV}(\%)^{*}$ & & $0.993(0.987-1.000)$ & & & 0.038 \\
\hline 6-MWD* & & $0.994(0.991-0.998)$ & & & $<0.001$ \\
\hline $\mathrm{PaO}_{2}(\mathrm{kPa}) \leq 7 . \mathrm{I}$ & & $5.135(2.415-10.917)$ & & & $<0.001$ \\
\hline
\end{tabular}

Notes: *HR represents change of risk of mortality, if parameter increases by unit. Desaturation, greatest decrease of $\mathrm{SpO}_{2}$ during 6-MWT (\%) $>4 \%$ and/or minimal $\mathrm{SpO}_{2}$ during (after) 6-MWT (\%) <90\%. Bold p-values represent statistically significant differences in mortality between tested end-points.

Abbreviations: AUC, area under curve; 6-MWT, 6-minute walking test; BMI, body mass index; BODE, body-mass index, airflow obstruction, dyspnea, and exercise; $\mathrm{HR}$, hazard ratio; TLC, total lung capacity; $\mathrm{SpO}_{2}$, basal peripheral capillary oxygen saturation; $\mathrm{PaO}_{2}$, partial pressure of oxygen in arterial blood; $\mathrm{PaCO}$, partial pressure of arterial carbon dioxide; $\mathrm{TL}_{\mathrm{co}}$, transfer factor for carbon monoxide; $\mathrm{RV}$, residual volume. 
Table S3 Relationship between comorbidities and all-cause mortality $(\mathbf{A})$; relationship between comorbidity and $\mathrm{PaO}_{2}(\mathbf{B})$; relationship between comorbidity and $\mathrm{PaCO}_{2}(\mathbf{C})$

\begin{tabular}{|c|c|c|c|}
\hline \multirow[t]{2}{*}{ Comorbidity } & \multicolumn{2}{|l|}{ Death } & \multirow[t]{2}{*}{$p$-value } \\
\hline & No & Yes & \\
\hline \multicolumn{4}{|l|}{$\mathbf{A}$} \\
\hline Atopy & 75 (12.4\%) & II (9.2\%) & 0.357 \\
\hline Asthma & $66(10.9 \%)$ & $9(7.5 \%)$ & 0.325 \\
\hline Coronary artery disease & $149(24.6 \%)$ & $39(32.5 \%)$ & 0.087 \\
\hline Heart failure & $88(14.5 \%)$ & 27 (22.5\%) & 0.039 \\
\hline Atrial fibrillation & $74(12.2 \%)$ & $16(13.3 \%)$ & 0.762 \\
\hline Hypertension & $34 \mid(56.4 \%)$ & $72(60.0 \%)$ & $0.48 I$ \\
\hline Syncope & $29(4.8 \%)$ & $7(5.8 \%)$ & 0.645 \\
\hline Tumor & $79(13.1 \%)$ & 27 (22.5\%) & 0.011 \\
\hline Osteoporosis & $85(14.0 \%)$ & $15(12.6 \%)$ & 0.772 \\
\hline Diabetes mellitus & $129(21.3 \%)$ & $26(21.7 \%)$ & 0.904 \\
\hline Anemia & $68(11.2 \%)$ & $21(17.5 \%)$ & 0.067 \\
\hline Depression & $109(18.0 \%)$ & $35(29.2 \%)$ & 0.008 \\
\hline \multirow[t]{3}{*}{ Ulcer disease } & $118(19.5 \%)$ & $22(18.3 \%)$ & 0.899 \\
\hline & \multicolumn{2}{|l|}{ Comorbidity } & \multirow[t]{2}{*}{$p$-value } \\
\hline & No & Yes & \\
\hline \multicolumn{4}{|l|}{ B } \\
\hline Atopy & 8.8 (।.6); 8.7 (6.3-II.7) & 9.4 (I.7); 9.4 (7.I-II.8) & 0.020 \\
\hline Asthma & $8.8(1.6) ; 8.8(6.3-11.8)$ & 9.1 (1.5); 9.3 (6.3-11.7) & 0.262 \\
\hline Coronary artery disease & 8.9 (1.6); 8.9 (6.3-11.8) & 8.6 (I.7); $8.4(6.1-11.2)$ & 0.036 \\
\hline Heart failure & 9.0 (1.6); 8.9 (6.6-II.8) & 8.0 (1.7); $7.8(5.3-10.9)$ & $<0.001$ \\
\hline Atrial fibrillation & $8.8(1.6) ; 8.8(6.3-11.8)$ & 8.9 (I.6); $8.9(6.1-11.2)$ & 0.644 \\
\hline Hypertension & 8.9 (I.6); 9.0 (6.4-II.3) & 8.8 (I.7); 8.7 (6.I-II.9) & 0.339 \\
\hline Syncope & 8.8 (I.6); $8.8(6.3-11.7)$ & 9.4 (1.9); $9.0(6.5-12.5)$ & 0.201 \\
\hline Tumor & $8.8(1.6) ; 8.8(6.4-11.7)$ & $8.9(1.8) ; 9.0(5.9-12.2)$ & 0.708 \\
\hline Osteoporosis & $8.8(1.6) ; 8.9$ (6.4-I1.7) & 8.8 (1.9); $8.6(6.0-12.0)$ & 0.808 \\
\hline Diabetes mellitus & 8.9 (1.7); 8.9 (6.3-11.9) & 8.6 (I.5); 8.6 (6.4-II.3) & 0.038 \\
\hline Anemia & 8.9 (1.6); 8.9 (6.4-I1.7) & $8.6(1.9) ; 8.4(5.5-12.2)$ & 0.307 \\
\hline Depression & 8.8 (I.6); 8.8 (6.3-II.7) & 9.1 (1.8); 9.1 (6.4-12.2) & 0.197 \\
\hline Ulcer disease & 8.8 (I.6); 8.7 (6.4-II.7) & 9.1 (1.7); 9.3 (6.0-II.9) & 0.067 \\
\hline \multicolumn{4}{|l|}{ C } \\
\hline Atopy & $5.3(0.9) ; 5.2(4.0-6.8)$ & $5.0(0.6) ; 5.0(4.1-6.2)$ & 0.046 \\
\hline Asthma & $5.3(0.9) ; 5.2(4.0-6.8)$ & $5.0(0.8) ; 4.9(3.8-5.7)$ & 0.025 \\
\hline Coronary artery disease & $5.2(0.9) ; 5.2(4.0-6.8)$ & $5.3(0.9) ; 5.2(4.2-6.8)$ & 0.918 \\
\hline Heart failure & $5.2(0.8) ; 5.1(3.9-6.4)$ & $5.6(0.9) ; 5.4(4.4-7.2)$ & $<0.001$ \\
\hline Atrial fibrillation & $5.2(0.9) ; 5.1(4.0-6.8)$ & $5.3(0.8) ; 5.2(3.9-6.7)$ & 0.089 \\
\hline Hypertension & $5.2(0.8) ; 5.2(3.9-6.8)$ & $5.2(0.9) ; 5.2(4.2-6.7)$ & $0.87 \mid$ \\
\hline Syncope & $5.2(0.9) ; 5.2(4.0-6.8)$ & $5.2(0.9) ; 5.1 \quad(3.9-6.9)$ & 0.614 \\
\hline Presyncope & $5.2(0.9) ; 5.2(4.0-6.8)$ & $5.2(0.7) ; 5.2(3.9-6.2)$ & 0.974 \\
\hline Tumor & $5.3(0.8) ; 5.2(4.2-6.8)$ & 5.1 (I.0); $5.2(3.9-6.8)$ & 0.538 \\
\hline Osteoporosis & $5.3(0.8) ; 5.2(4.2-6.8)$ & $5.1(0.9) ; 5.1$ (3.7-6.8) & 0.153 \\
\hline Diabetes mellitus & $5.2(0.9) ; 5.1(3.9-6.8)$ & $5.4(0.8) ; 5.3(4.3-6.8)$ & 0.010 \\
\hline Anemia & $5.2(0.8) ; 5.1(4.0-6.8)$ & $5.4(0.9) ; 5.4(3.9-6.9)$ & 0.122 \\
\hline Depression & $5.2(0.8) ; 5.2(4.0-6.7)$ & $5.4(1.1) ; 5.2(3.9-7.0)$ & 0.302 \\
\hline Ulcer disease & $5.3(0.8) ; 5.2(4.1-6.8)$ & $5.2(1.1) ; 5.0(3.9-6.8)$ & 0.102 \\
\hline
\end{tabular}

Notes: Parameters are described by absolute (relative) frequencies and tested by Fisher's exact test (A). Parameters are described by mean (SD); median (5th and 95 th percentiles) and tested by Mann-Whitney test (B, C). Bold p-values represent statistically significant differences in mortality between tested end-points. Abbreviation: $\mathrm{PaCO}_{2}$, partial pressure of arterial carbon dioxide. 
Table S4 Comparison of parameters between groups according to valid data $(n=725)$

\begin{tabular}{|c|c|c|c|c|c|}
\hline Tested parameter & $\begin{array}{l}\text { Without 6-MWT } \\
\text { and ABG }(n=133)\end{array}$ & $\begin{array}{l}\text { Only with } \\
\text { 6-MWT (n=20I) }\end{array}$ & $\begin{array}{l}\text { Only with } \\
\text { ABG }(n=40)\end{array}$ & $\begin{array}{l}\text { With 6-MWT } \\
\text { and ABG }(n=35 I)\end{array}$ & $p$-value \\
\hline \multicolumn{6}{|l|}{ Demography } \\
\hline Sex-men & 97 (72.9\%) & $146(72.6 \%)$ & $25(62.5 \%)$ & $252(71.8 \%)$ & 0.597 \\
\hline Age at inclusion & $67.4(10.3)$ & $65.3(10.0)$ & $69.4(9.3)$ & $67.0(8.5)$ & 0.078 \\
\hline BMI & $26.7(5.6)$ & $27.1(5.4)$ & $25.9(4.7)$ & $26.9(6.1)$ & 0.553 \\
\hline \multicolumn{6}{|l|}{ Symptoms } \\
\hline mMRC & $2.0(I .1)$ & $2.3(0.9)$ & $2.5(1.1)$ & $2.2(1.2)$ & 0.007 \\
\hline CAT & $17.3(8.2)$ & $15.5(7.2)$ & $17.5(8.0)$ & $15.5(7.9)$ & 0.067 \\
\hline \multicolumn{6}{|l|}{ Exacerbations } \\
\hline Treated at home (moderate) & $0.6(I . I)$ & $0.8(1.2)$ & $0.9(1.1)$ & $0.9(1.5)$ & 0.223 \\
\hline Requiring hospitalization (severe) & $0.2(0.6)$ & $0.2(0.5)$ & $0.7(0.8)$ & $0.5(0.9)$ & $<0.001$ \\
\hline Total & $0.8(1.4)$ & $1.0(1.4)$ & $1.6(1.4)$ & $1.4(1.9)$ & $<0.001$ \\
\hline \multicolumn{6}{|l|}{ Lung function } \\
\hline $\mathrm{FEV}_{1}(\%)$ & $45.3(11.2)$ & $47.7(11.6)$ & $44.8(12.9)$ & $43.2(11.4)$ & $<0.001$ \\
\hline FVC (\%) & $71.8(16.8)$ & $69.1(15.2)$ & $71.3(15.5)$ & $68.0(19.5)$ & 0.057 \\
\hline $\mathrm{TL}_{\mathrm{co}}(\%$ pred $)$ & $52.1(21.9)$ & $62.1(24.1)$ & $48.6(16.2)$ & $49.4(21.0)$ & $<0.001$ \\
\hline
\end{tabular}

Notes: Categorical parameters are described by absolute (relative) frequency. Differences are tested by Fisher's exact test. Continuous parameters are described by mean (SD). Differences are tested by Kruskal-Wallis test. Significant differences are indicated in bold.

Abbreviations: 6-MWT, 6-minute walking test; ABG, arterial blood gas; BMI, body mass index; CAT, COPD Assessment Test; FEV , forced expiratory volume in I second; FVC, forced vital capacity; mMRC, modified Medical Research Council dyspnea scale; pred, predicted value; $\mathrm{TL}_{c o}$, transfer factor for carbon monoxide.

Table S5 $\mathrm{SpO}_{2}$ according to physical examination $(\mathrm{n}=725)(\mathbf{A})$, correlation between $\mathrm{SpO}_{2}$ (physical examination*) and $\mathrm{SpO}_{2}\left(6-\mathrm{MWT}^{\circ}\right.$ ) $(\mathrm{n}=552)(\mathbf{B})$

Valid N, mean (SD), median (5th and 95th percentile)

A

$\mathrm{SpO}_{2}$ (physical examination*) $\quad \mathrm{n}=725 ; 93.8(4.6) ; 95.0(87.0 ; 98.0)$

$\mathrm{SpO}_{2}\left(6-\mathrm{MWT}^{\circ}\right) \quad \mathrm{n}=552 ; 94.5(3.6) ; 95.0$ (88.0; 98.0)

Spearman's coefficient of correlation ( $p$-value)

B

$\mathrm{SpO}_{2} \quad \mathrm{n}=552 ; 0.779(<\mathbf{0 . 0 0 I})$

Note: *Mandatory parameter available in all COPD subjects, ${ }^{\circ}$ optional (nonmandatory) parameter used in our analysis.

Abbreviations: 6-MWT, 6-minute walking test; $\mathrm{SpO}_{2}$, peripheral capillary oxygen saturation.

\section{Publish your work in this journal}

The International Journal of COPD is an international, peer-reviewed journal of therapeutics and pharmacology focusing on concise rapid reporting of clinical studies and reviews in COPD. Special focus is given to the pathophysiological processes underlying the disease, intervention programs, patient focused education, and self management protocols.

\section{Dovepress}

This journal is indexed on PubMed Central, MedLine and CAS. The manuscript management system is completely online and includes a very quick and fair peer-review system, which is all easy to use. Visit $\mathrm{http}: / /$ www.dovepress.com/testimonials.php to read real quotes from published authors. 